\title{
Diagnostic accuracy of the gastric cancer T-category with respect to tumor localization
}

\author{
Kenji Nanishi ${ }^{1} \cdot$ Katsutoshi Shoda ${ }^{1} \cdot$ Takeshi Kubota $^{1}$ (i) $\cdot$ Toshiyuki Kosuga $^{1} \cdot$ Hirotaka Konishi $^{1} \cdot$ Atsushi Shiozaki $^{1}$. \\ Hitoshi Fujiwara ${ }^{1} \cdot$ Kazuma Okamoto $^{1} \cdot$ Eigo Otsuji $^{1}$
}

Received: 25 April 2020 / Accepted: 19 August 2020 / Published online: 26 August 2020

(C) The Author(s) 2020

\begin{abstract}
Purpose Diagnosing early gastric cancer (EGC) or advanced gastric cancer (AGC) according to T-category is important for optimal GC treatment; however, the clinical and pathological diagnosis of tumor depths can sometimes vary. This study investigated the accuracy of clinical diagnosis of the tumor depth from the viewpoint of tumor localization and prognosis of patients with GC with discordance between clinical and pathological findings.

Methods This study enrolled 741 patients with primary GC who underwent curative gastrectomy. Based on the clinical and pathological diagnosis of T-category, the patients were classified into four groups: Early-look EGC, Early-look AGC, Advancedlook EGC, and Advanced-look AGC. Tumor localization was classified longitudinally (the upper [U], middle [M], and lower [L] parts and cross-sectionally (the anterior [Ant] and posterior [Post] walls, and the lesser [Less] and greater [Gre] curvatures).

Results Of the 462 clinical EGC cases, 52 were Early-look AGC cases that exhibited a significant association of tumor localization with the Post and Less in the U and M locations (UM-PL; $p=0.037)$. An Advanced-look EGC $(p=0.031)$ and Advanced-look AGC $(p=0.025)$ were independent prognostic factors for relapse-free survival each in pathological EGC and AGC, respectively. Conclusions Patients with clinically diagnosed EGC but with pathologically diagnosed AGC more frequently presented tumor in the UM-PL than in any other location. Selection of therapeutic strategy according to the clinical diagnosis might be critical; however, it should be also considered that the accuracy of preoperative assessments varies with tumor localization.
\end{abstract}

Keywords Gastric cancer $\cdot$ Clinical staging $\cdot$ Diagnostic discordance $\cdot$ Tumor localization

\section{Introduction}

Gastric cancer (GC) has been found to be the fifth most common cancer and the third leading cause of cancer-related death worldwide [1]. According to currently available guidelines based on previous studies of GC, the optimal treatment for each patient is determined by finely stratified staging $[2,3]$; however, the endoscopic tumor depth may be different from

Electronic supplementary material The online version of this article (https://doi.org/10.1007/s00423-020-01971-3) contains supplementary material, which is available to authorized users.

Takeshi Kubota tkubot@koto.kpu-m.ac.jp

1 Division of Digestive Surgery, Department of Surgery, Kyoto Prefectural University of Medicine, 465 Kawaramachi Hirokoji Kajii-cho, Kamigyo-ku, Kyoto 602-8566, Japan the pathologic tumor depth [4]. Clinical staging of GC has become important for determining the therapeutic strategy. In accordance with a previous study, we established whether it is an early gastric cancer (EGC) only by T-category [5]; moreover, distinguishing EGC from advanced GC (AGC) is particularly meaningful because EGC has the option to undergo endoscopic resection and laparoscopic surgery by clinical staging at many institutions [6-9]. However, clinical EGC (cEGC) is sometimes revealed to be pathological AGC (pAGC) upon examination of the resected specimen, while clinical AGC (cAGC) is often determined to be pathological EGC (pEGC). Regarding the cases in which these discrepancies occur, the detailed clinical features have often not yet been clarified and remain important issues to be solved.

Cross-sectional classification may be as important as longitudinal classification for GC therapy. Previous studies have demonstrated that the expressions of various molecules change depending upon the location in the stomach [10]; therefore, the characteristics of GC may vary according to 
the tumor location. Other studies have suggested that the prognosis varies depending on the localization of GC and that, in addition to longitudinal classifications (the upper [U], middle $[\mathrm{M}]$, and lower $[\mathrm{L}]$ parts), cross-sectional classifications (the anterior [Ant] and posterior [Post] walls, and the lesser [Less] and greater [Gre] curvatures) are also associated with longterm survival [11].

The aim of the present study was to investigate the accuracy of the clinical diagnosis of tumor depth from the viewpoint of tumor localization and to evaluate the clinicopathological features and prognosis of GC in patients with discordant clinical and pathological findings.

\section{Materials and methods}

\section{Patients}

Between 2008 and 2017, a total of 917 patients with GC underwent gastrectomy at Kyoto Prefectural University of Medicine Hospital. Patients with residual GC, esophagogastric junction cancer, gastric tube cancer, $\mathrm{GC}$ occupying the gastric circumference, multiple GC, administration of neoadjuvant chemotherapy, and re-operation according to the pathological result were excluded from this study. A total of 741 patients with primary GC who underwent curative gastrectomy with D1 plus or D2 lymph node dissection at our university hospital were enrolled in the present retrospective study (Fig. S1).

All included patients had undergone endoscopy and multidetector-row computed tomography (MDCT) before surgery, and the preoperative endoscopic images were reviewed by expert gastrointestinal endoscopists. In our institution, expert gastrointestinal endoscopists classify GC as either EGC or AGC with conventional endoscopy according to the guidelines of the Japan Gastroenterological Endoscopy Society (JGES) as the first step of clinical staging for GC, and if necessary, using endoscopic ultrasound (EUS) or CT as an auxiliary device; subsequently, the invasion to an adjacent organ, lymph node metastasis, and distant metastasis are evaluated by $\mathrm{CT}$ and positron-emission tomography/CT (PET/CT). Clinical and pathological staging was performed using the eighth Union for International Cancer Control (UICC) tumor-lymph node-metastasis (TNM) staging classification [12] and the 15th Japanese Classification of Gastric Carcinoma (JCGC) scheme [13]. EGC was defined as invasive carcinoma confined to mucosa and/or submucosa, irrespective of lymph node metastasis [5].

In addition, the study participants were classified, according to T-category, into the following four groups: patients who were clinically diagnosed with cEGC but who were found to have pAGC during the postoperative pathological examination (Early-look AGC), those diagnosed with EGC both clinically and pathologically (Early-look
EGC), those clinically diagnosed with cAGC but who were found to have $\mathrm{pEGC}$ during the postoperative pathological examination (Advanced-look EGC), and those with AGC diagnosed both clinically and pathologically (Advancedlook AGC). For prognostic analysis, the overall survival (OS) and relapse-free survival (RFS) rates were analyzed in 662 patients, excluding cases with synchronous or metachronous other cancer within 5 years before surgery. Adjuvant chemotherapy was indicated for patients with pathological stage (pStage) II or III (excluded with pT1 and pT3N0), and administration was finally decided considering the patient's condition including performance status and patient's expectations. The chemotherapy regimen was basically S-1 single agent for 1 year, and platinum regimens or taxane regimen were added for pStage III if the patient's condition was tolerable. Follow-up procedures consisting of blood investigations and abdominal ultrasound and CT scans were performed every 36 months after surgery. All procedures were performed in accordance with the ethical standards of the responsible committees on human experimentation (institutional and national) and the 1964 Declaration of Helsinki and later versions. Informed consent was obtained from all patients prior to inclusion in this study.

\section{Definition of sectional location}

First, we investigated the clinical features for the longitudinal and cross-sectional tumor locations, respectively. Moreover, tumors were classified into six groups according to the combination of their longitudinal and cross-sectional locations, as follows: Post or Less in the U region (U-PL), Ant or Gre in the U region (U-AG), Post or Less in the M region (M-PL), Ant or Gre in the $\mathrm{M}$ region (M-AG), Post or Less in the $\mathrm{L}$ region (LPL), and Ant or Gre in the L region (L-AG) (Fig. 1).

\section{Histological evaluation}

In accordance with the 15th JCGC scheme [13], the primary tumors were cut crosswise through the center of the tumor. Tumors were sectioned in their entirety parallel to the reference line at $5-\mathrm{mm}$ intervals. The resected specimens were fixed in $10 \%$ buffered formalin solution, embedded in paraffin, and stained with hematoxylin and eosin. The clinicopathological features of all study participants were obtained from their hospital records based on the eighth UICC TNM classification [12] and the 15th JCGC scheme [13].

\section{Statistical analysis}

Fisher's exact probability test and the chi-squared test were performed to compare categorical variables between the two groups, while non-parametric tests were used for subgroup 
Fig. 1 Preoperative diagnostic accuracy according to the tumor location. a Scatter plots of the clinical T-category and pathological T-category according to the tumor location are shown. White areas show concordant cases, and gray areas show discordant cases between clinical and pathological diagnoses. A dark gray area indicates a frequency of discordant cases higher than that of a light gray area. b Representative endoscopic images of Early-look AGC (left panel) and Advanced-look EGC (right panel) $\mathbf{a}$
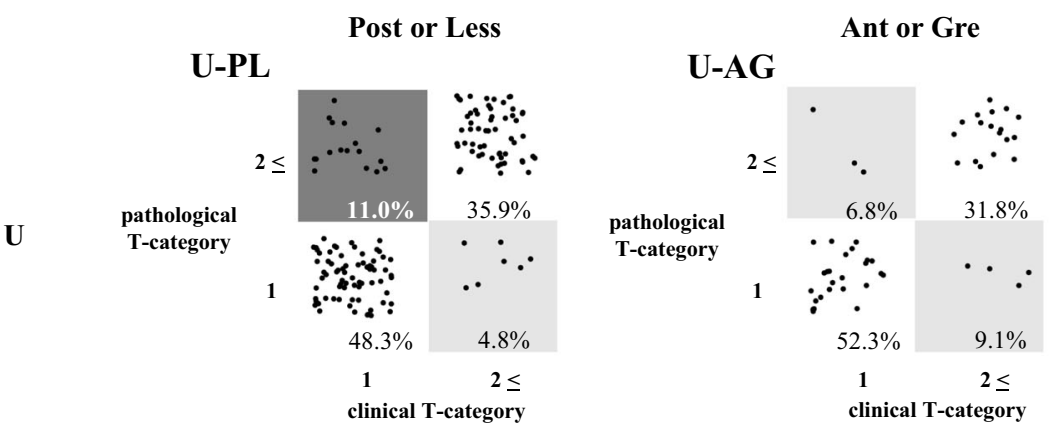

M-PL
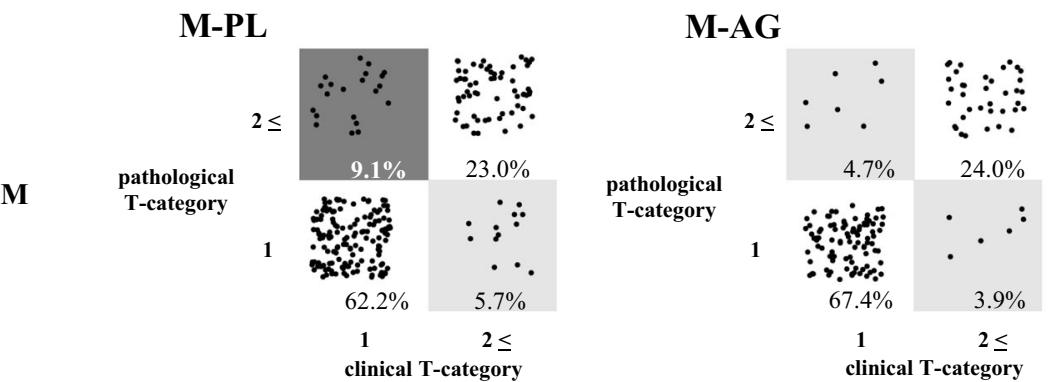

L-PL
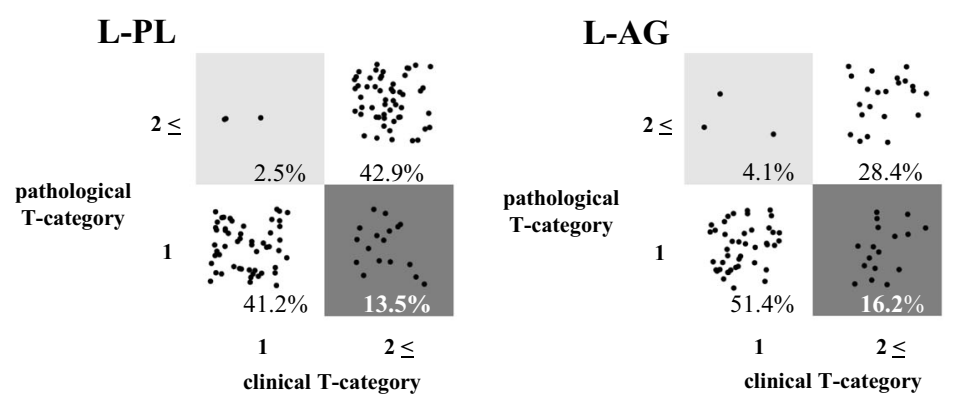

b

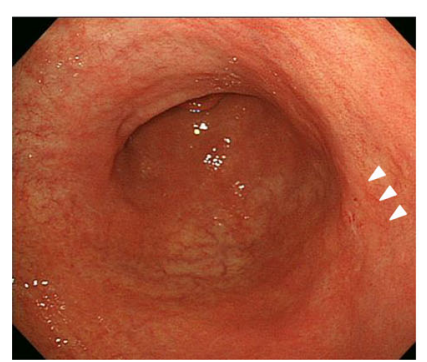

comparisons. Multivariate analysis was performed using multinomial logistic regression to examine clinicopathologic factors affecting to endoscopic diagnosis. OS and RFS rates were calculated via Kaplan-Meier analysis, with the date of gastrectomy designated as the starting point. Differences in survival rates were examined by log-rank test. The Cox proportional hazards models were used to estimate potential clinicopathologic characteristics affecting prognosis. All statistical analysis was performed using JMP version 13 (ASA Institute, Cary, $\mathrm{NC}$, USA). All statistical tests except for the paired tests were two-sided. Statistical significance was accepted at $p<0.05$.

\section{Results}

\section{Clinicopathological characteristics}

This study evaluated 741 patients who met all of the above-defined criteria, with 410, 52, 57, and 222 patients categorized into the Early-look EGC, Early-look AGC, Advanced-look EGC, and Advanced-look AGC groups, respectively (Table 1$)$. Age $(p<0.001)$, tumor longitudinal localization $(p<0.001)$, tumor size $(p<0.001)$, macroscopic appearance $(p<0.001)$, surgical approach 
Table 1 Correlation between clinicopathological characteristics and endoscopic diagnosis of tumor depth for GC

\begin{tabular}{|c|c|c|c|c|c|}
\hline Variables & $\begin{array}{l}\text { Early-look EGC }{ }^{\mathrm{a}}(\%) \\
n=410\end{array}$ & $\begin{array}{l}\text { Early-look AGC }{ }^{\mathrm{a}}(\%) \\
n=52\end{array}$ & $\begin{array}{l}\text { Advanced-look EGC }{ }^{\mathrm{a}}(\%) \\
n=57\end{array}$ & $\begin{array}{l}\text { Advanced-look AGC }{ }^{\mathrm{a}}(\%) \\
n=222\end{array}$ & $p$ value \\
\hline \multicolumn{6}{|l|}{ Age } \\
\hline $\begin{array}{l}\text { Mean } \pm \mathrm{SD} \\
\quad \text { (years) }\end{array}$ & $65.3 \pm 0.5$ & $65.5 \pm 1.7$ & $67.7 \pm 1.5$ & $68.8 \pm 0.8$ & $<0.001$ \\
\hline \multicolumn{6}{|l|}{ Sex } \\
\hline M & $268(65.4 \%)$ & $39(75.0 \%)$ & $38(66.7 \%)$ & $161(72.5 \%)$ & \multirow[t]{2}{*}{0.203} \\
\hline $\mathrm{F}$ & $142(34.6 \%)$ & $13(25.0 \%)$ & $19(33.3 \%)$ & $61(27.5 \%)$ & \\
\hline \multicolumn{6}{|l|}{ BMI } \\
\hline $\begin{array}{c}\text { Mean } \pm \text { SD } \\
\left(\mathrm{kg} / \mathrm{m}^{2}\right)\end{array}$ & $22.8 \pm 3.5$ & $21.9 \pm 3.5$ & $23.0 \pm 3.8$ & $22.2 \pm 3.2$ & 0.104 \\
\hline \multicolumn{6}{|c|}{ Histopathology (biopsy) } \\
\hline Intestinal type & $223(55.2 \%)$ & $22(44.0 \%)$ & $33(58.9 \%)$ & $128(60.1 \%)$ & \multirow[t]{3}{*}{0.241} \\
\hline Diffuse type & $181(44.8 \%)$ & $28(56.0 \%)$ & $23(41.1 \%)$ & $85(39.9 \%)$ & \\
\hline Unknown & 6 & 2 & 1 & 9 & \\
\hline \multicolumn{6}{|c|}{ Tumor localization 1} \\
\hline $\mathrm{U}$ & $93(22.7 \%)$ & $19(36.5 \%)$ & $11(19.3 \%)$ & $66(29.7 \%)$ & \multirow[t]{3}{*}{$<0.001$} \\
\hline M & $230(56.1 \%)$ & $27(51.9 \%)$ & $18(31.6 \%)$ & $84(37.8 \%)$ & \\
\hline $\mathrm{L}$ & $87(21.2 \%)$ & $6(11.5 \%)$ & $28(49.1 \%)$ & $72(32.4 \%)$ & \\
\hline \multicolumn{6}{|c|}{ Tumor localization 2} \\
\hline Post & $113(27.6 \%)$ & $14(26.9 \%)$ & $18(31.6 \%)$ & $54(24.3 \%)$ & \multirow[t]{4}{*}{0.247} \\
\hline Less & $149(36.3 \%)$ & $26(50.0 \%)$ & $18(31.6 \%)$ & $102(45.9 \%)$ & \\
\hline Ant & $69(16.8 \%)$ & $7(13.5 \%)$ & $9(15.8 \%)$ & $35(15.8 \%)$ & \\
\hline Gre & $79(19.3 \%)$ & $5(9.6 \%)$ & $12(21.1 \%)$ & $31(14.0 \%)$ & \\
\hline \multicolumn{6}{|l|}{ Tumor size (mm) } \\
\hline$\geq 20$ & $289(71.2 \%)$ & $49(94.2 \%)$ & $50(87.7 \%)$ & $220(99.1 \%)$ & \multirow[t]{3}{*}{$<0.001$} \\
\hline$<20$ & $117(28.8 \%)$ & $3(5.8 \%)$ & $7(12.3 \%)$ & $2(0.9 \%)$ & \\
\hline Unknown & 4 & 0 & 0 & 0 & \\
\hline \multicolumn{6}{|c|}{ Macroscopic appearance } \\
\hline Localized & $16(3.9 \%)$ & $3(5.8 \%)$ & $20(35.1 \%)$ & $87(39.2 \%)$ & \multirow[t]{2}{*}{$<0.001$} \\
\hline Diffuse & $394(96.1 \%)$ & $49(94.2 \%)$ & $37(64.9 \%)$ & $135(60.8 \%)$ & \\
\hline \multicolumn{6}{|l|}{ Surgical approach } \\
\hline Open & $48(11.7 \%)$ & $11(21.2 \%)$ & $40(70.2 \%)$ & $199(89.6 \%)$ & \multirow[t]{2}{*}{$<0.001$} \\
\hline Laparoscopic & $362(88.3 \%)$ & $41(78.8 \%)$ & $17(29.8 \%)$ & $23(10.4 \%)$ & \\
\hline \multicolumn{6}{|c|}{ Surgical procedure } \\
\hline TG & $66(16.1 \%)$ & $15(28.8 \%$ & $18(31.6 \%)$ & $101(45.5 \%)$ & \multirow[t]{3}{*}{$<0.001$} \\
\hline DG & $293(71.5 \%)$ & $31(59.6 \%)$ & $38(66.7 \%)$ & $116(52.3 \%)$ & \\
\hline Others & $51(12.4 \%)$ & $6(11.5 \%)$ & $1(1.8 \%)$ & $5(2.3 \%)$ & \\
\hline \multicolumn{6}{|c|}{ Lymph node dissection } \\
\hline$<\mathrm{D} 2$ & $387(94.4 \%)$ & $47(90.4 \%)$ & $17(29.8 \%)$ & $52(23.4 \%)$ & \multirow[t]{2}{*}{$<0.001$} \\
\hline$\geq \mathrm{D} 2$ & $23(5.6 \%)$ & $5(9.6 \%)$ & $40(70.2 \%)$ & $170(76.6 \%)$ & \\
\hline \multicolumn{6}{|c|}{ Adjuvant chemotherapy } \\
\hline$(+)$ & $13(3.2 \%)$ & $14(27.5 \%)$ & $5(8.9 \%)$ & $103(47.9 \%)$ & \multirow[t]{6}{*}{$<0.001$} \\
\hline S-1 & 12 & 12 & 4 & 83 & \\
\hline S-1 + platinum & 0 & 1 & 1 & 13 & \\
\hline Others & 1 & 1 & 0 & 7 & \\
\hline$(-)$ & $396(96.8 \%)$ & $37(72.5 \%)$ & $51(91.1 \%)$ & $112(52.1 \%)$ & \\
\hline Unknown & 1 & 1 & 1 & 7 & \\
\hline
\end{tabular}

${ }^{\text {a }}$ Disease stage was defined in accordance with the International Union Against Cancer 7th tumor-lymph node-metastases classification using surgicalpathological findings

${ }^{\mathrm{b}}$ According to Lauren classification using most predominant histopathological finding

$E G C$, early gastric cancer; $A G C$, advanced gastric cancer; $S D$, standard deviation; $B M I$, body mass index; $T G$, total gastrectomy; $D G$, distal gastrectomy Italic entries show $p$ value $<0.05$

$(p<0.001)$, surgical procedure $(p<0.001)$, lymph node dissection $(p<0.001)$, and adjuvant chemotherapy $(p<0.001)$ were significantly different among above four groups.

\section{Predictable factors related to discordance between clinical and pathological findings}

Although no significant differences were found when comparing the cross-sectional locations identified among the four 
groups (Post, Less, Ant, and Gre), we did recognize a tendency for more frequent occurrences of Early-look AGC in the PL regions $(p=0.065)$. Scatterplots of the clinical and pathological diagnoses in relation to the six locations are shown (Fig. 1). Early-look AGC was found in $11.0 \%$ in the U-PL and
$9.1 \%$ in the M-PL, which were higher frequencies than those of the other locations. Moreover, the U-PL and M-PL (UMPL) areas were more correlated with Early-look AGC cases than the other areas among the cEGC patients $(p=0.012)$. Separately, in the cAGC patients, the L area was significantly

Table 2 Clinicopathological risk factors for diagnosing pAGC as cEGC

\begin{tabular}{|c|c|c|c|c|c|c|}
\hline \multirow[t]{2}{*}{ Variables } & \multirow{2}{*}{$\begin{array}{l}\mathrm{pEGC}(\%) \\
n=410\end{array}$} & \multirow{2}{*}{$\begin{array}{l}\mathrm{pAGC}(\%) \\
n=52\end{array}$} & \multirow[t]{2}{*}{ Univariate analysis } & \multicolumn{3}{|c|}{ Multivariate analysis } \\
\hline & & & & Odds ratio & $p$ value & $95 \% \mathrm{CI}$ \\
\hline \multicolumn{7}{|l|}{ Age } \\
\hline$<65$ & $173(42.2 \%)$ & $24(46.2 \%)$ & 0.587 & & & \\
\hline$\geq 65$ & $237(57.8 \%)$ & $28(53.8 \%)$ & & & & \\
\hline \multicolumn{7}{|l|}{ Sex } \\
\hline M & $268(65.4 \%)$ & $39(75.0 \%)$ & 0.212 & & & \\
\hline $\mathrm{F}$ & $142(34.6 \%)$ & $13(25.0 \%)$ & & & & \\
\hline \multicolumn{7}{|l|}{ BMI } \\
\hline$\geq 22$ & $237(57.9 \%)$ & $26(50.0 \%)$ & 0.300 & & & \\
\hline$<22$ & $172(42.1 \%)$ & $26(50.0 \%)$ & & & & \\
\hline \multicolumn{7}{|c|}{ Histopathology ${ }^{\mathrm{a}}$ (biopsy) } \\
\hline Intestinal type & $223(55.2 \%)$ & $22(44.0 \%)$ & 0.175 & & & \\
\hline Diffuse type & $181(44.8 \%)$ & $28(56.0 \%)$ & & & & \\
\hline Unknown & 6 & 2 & & & & \\
\hline \multicolumn{7}{|c|}{ Tumor localization } \\
\hline UM-PL & $213(52.0 \%)$ & $37(71.2 \%)$ & 0.012 & 2.18 & 0.037 & $1.04-4.54$ \\
\hline Other & $197(48.0 \%)$ & $15(28.8 \%)$ & & & & \\
\hline \multicolumn{7}{|l|}{ Tumor size $(\mathrm{mm})$} \\
\hline$<20$ & $289(71.2 \%)$ & $49(94.2 \%)$ & $<0.001$ & 4.68 & 0.014 & $1.37-16.02$ \\
\hline$\geq 20$ & $117(28.8 \%)$ & $3(5.8 \%)$ & & & & \\
\hline \multicolumn{7}{|c|}{ Macroscopic appearance } \\
\hline Localized & $16(3.9 \%)$ & $3(5.8 \%)$ & 0.461 & & & \\
\hline Diffuse & $394(96.1 \%)$ & $49(94.2 \%)$ & & & & \\
\hline \multicolumn{7}{|c|}{ Surgical approach } \\
\hline Open & $48(11.7 \%)$ & $11(21.2 \%)$ & 0.055 & & & \\
\hline Laparoscopic & $362(88.3 \%)$ & $41(78.8 \%)$ & & & & \\
\hline \multicolumn{7}{|c|}{ Surgical procedure } \\
\hline TG & $66(18.4 \%)$ & $15(32.6 \%)$ & 0.023 & 1.56 & 0.243 & $0.74-3.28$ \\
\hline DG & $293(81.6 \%)$ & $31(67.4 \%)$ & & & & \\
\hline Others & 51 & 6 & & & & \\
\hline \multicolumn{7}{|c|}{ Lymph node dissection } \\
\hline$<\mathrm{D} 2$ & $387(94.4 \%)$ & $47(90.4 \%)$ & 0.254 & & & \\
\hline$\geq \mathrm{D} 2$ & $23(5.6 \%)$ & $5(9.6 \%)$ & & & & \\
\hline \multicolumn{7}{|c|}{ Adjuvant chemotherapy } \\
\hline$(+)$ & $13(3.2 \%)$ & $14(27.5 \%)$ & $<0.001$ & 8.85 & $<0.001$ & $3.51-22.29$ \\
\hline$(-)$ & $396(96.8 \%)$ & $37(72.5 \%)$ & & & & \\
\hline Unknown & 1 & 1 & & & & \\
\hline
\end{tabular}

${ }^{a}$ According to Lauren classification using most predominant histopathological finding

$c E G C$, clinical early gastric cancer; $p E G C$, pathological early gastric cancer; $p A G C$, pathological advanced gastric cancer; $C I$, confident interval; $B M I$, body mass index; $T G$, total gastrectomy; $D G$, distal gastrectomy

Italic entries show $p$ value $<0.05$ 
correlated with Advanced-look EGC cases in comparison with the other areas $(p=0.035)$.

Of the 462 cEGC patients, 52 cases had pAGC (Early-look AGC); these patients showed a significant association with tumor localization in the UM-PL $(p=0.037)$ and a larger tumor size $(p$ $<0.001$ ) in the multivariate analysis (Table 2). Conversely, among the 279 cAGC patients, 57 cases were included in the Advanced-look EGC group, and these cases showed a significant association with tumor localization in the $\mathrm{L}$ region $(p=0.021)$ and a smaller tumor size $(p=0.016)$ (Table S1).

\section{Clinical outcomes after surgery}

Figure 2 shows the prognostic impact of the preoperative endoscopic appearance in patients with GC. The analysis results divided into four groups (Early-look EGC, Advanced-look EGC, Early-look AGC, and Advanced-look AGC) revealed that the prognosis was significantly stratified for both OS $(p<0.001)$ and RFS $(p<0.001)$. When comparing the prognosis of patients with cEGC and cAGC according to the pTcategory (Early-look vs. Advanced-look EGC, Early-look vs. Advanced-look AGC) to focus on the impact of cT-category on the prognosis, we found that patients with cEGC on clinical estimation had a significantly better prognosis than patients with cAGC on clinical estimation in both comparisons. Among patients with pAGC on the pathological examination, the Early-look AGC cases showed significantly higher OS and RFS rates ( $p=0.004$ and $p=0.011$, respectively) than the Advanced-look AGC cases. The tendency was similar in the subgroup analysis conducted for each stage (pStage I/II/ III), although no significant difference was detected because of the limited number of cases. In the subgroup analysis, we analyzed only pEGC in pStage I and pAGC in pStage II/III, because of the uneven number of patients (Fig. S2). We then analyzed clinicopathological characteristics affecting prognosis in patients with pAGC. The Cox proportional hazards model revealed that low body mass index (RFS, $p=0.030$; OS, $p=0.021$ ), total gastrectomy (RFS, $p=0.004$; OS, $p=$ 0.024 ), D1 plus lymph node dissection (RFS, $p=0.044$; OS, $p=0.039$ ), pathological node-positive (RFS, $p=0.005$; OS, $p=0.008$ ), and cAGC (RFS, $p=0.007$; OS, $p=0.017$ ) were independent prognostic factors for RFS and OS in patients with pAGC (Table 3). As only a few patients with pAGC had $<20 \mathrm{~mm}$ tumor and few of them underwent laparoscopic gastrectomy with $>\mathrm{D} 2$ lymph node dissection, the tumor size and the surgical approach were excluded from the variables of multivariate analysis to maintain statistically reliability.

Among the patients with pEGC, the Advanced-look EGC cases exhibited a significantly poorer prognosis in terms of both OS and RFS $(p<0.001$ and $p<0.001$, respectively). In these cases, the Cox proportional hazards model showed that older age (RFS, $p=0.018$; OS, $p=0.015$ ), D1 plus lymph node dissection (RFS, $p=0.016$; OS, $p=0.024$ ), and adjuvant chemotherapy (RFS, $p=0.016$; OS, $p=0.013$ ) were independent prognostic factors for RFS and OS. Advanced-look EGC case designation for RFS $(p=0.016)$ and macroscopic diffuse appearance for OS $(p=0.039)$ were the independent prognostic factors (Table S2). Concerning the recurrence pattern, there
Table 3 Multivariate analysis for clinicopathological characteristics affecting prognosis in patients with pAGC

\begin{tabular}{|c|c|c|c|c|c|c|}
\hline \multirow[t]{2}{*}{ Variables } & \multicolumn{3}{|l|}{ RFS } & \multicolumn{3}{|l|}{ OS } \\
\hline & $\mathrm{HR}$ & $95 \% \mathrm{CI}$ & $p$ value & $\mathrm{HR}$ & $95 \% \mathrm{CI}$ & $p$ value \\
\hline Age $\geq 65$ (vs. $<65)$ & 0.81 & $0.43-1.57$ & 0.520 & 0.92 & $0.44-2.00$ & 0.829 \\
\hline Female (vs. male) & 1.24 & 0.582 .51 & 0.564 & 1.37 & $0.59-3.03$ & 0.456 \\
\hline BMI < 22 (vs. $\geq 22$ ) & 2.01 & $1.07-3.94$ & 0.030 & 2.40 & $1.14-5.28$ & 0.021 \\
\hline cAGC (vs. cEGC) & 4.85 & $1.49-22.16$ & 0.007 & 5.45 & $1.32-37.77$ & 0.017 \\
\hline $\begin{array}{l}\text { Macroscopic diffuse appearance } \\
\text { (vs. localized appearance) }\end{array}$ & 0.62 & $0.32-1.20$ & 0.156 & 0.51 & $0.24-4.17$ & 0.077 \\
\hline TG (vs. DG) & 2.54 & $1.36-4.87$ & 0.004 & 2.28 & $1.12-4.75$ & 0.024 \\
\hline Lymph node dissection $<$ D2 (vs. $\geq$ D2) & 2.25 & $1.02-4.75$ & 0.044 & 2.54 & $1.05-5.87$ & 0.039 \\
\hline 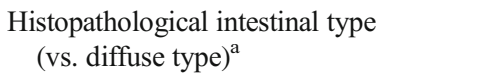 & 1.38 & $0.68-2.83$ & 0.369 & 1.13 & $0.49-2.62$ & 0.774 \\
\hline pN stage pN1-3 (vs. pN0) & 2.54 & $1.32-5.27$ & 0.005 & 2.81 & $1.31-6.62$ & 0.008 \\
\hline Lymphatic invasion (vs. negative) & 1.41 & $0.67-3.26$ & 0.379 & 0.94 & $0.42-2.34$ & 0.890 \\
\hline Venous invasion (vs. negative) & 0.89 & $0.47-1.74$ & 0.243 & 1.03 & $0.48-2.29$ & 0.934 \\
\hline Adjuvant chemotherapy (vs. absence) & 1.47 & $0.77-2.88$ & 0.156 & 1.20 & $0.56-2.62$ & 0.634 \\
\hline
\end{tabular}

${ }^{a}$ According to Lauren classification using most predominant histopathological finding

$p A G C$, pathological advanced gastric cancer; $c A G C$, clinical advanced gastric cancer; $c E G C$; clinical early gastric cancer; $R F S$, relapse-free survival; $O S$, overall survival; $H R$, hazard ratio; $C I$, confident interval; $B M I$, body mass index; $T G$, total gastrectomy; $D G$, distal gastrectomy

Italic entries show $p$ value $<0.05$ 
were no significant differences in the comparison between the Advanced-look EGC and Early-look EGC cases.

\section{Discussion}

To determine the appropriate treatment for GC, ensuring an accurate preoperative assessment of the tumor depth has become increasingly important due to the development of minimally invasive treatment modalities such as endoscopic resection and laparoscopic surgery. Japanese gastric cancer guidelines determine the indication of treatment according to cT-category. For endoscopic resection, the absolute indication $[14,15]$ is either differentiated type (approximately equal intestinal type) cT1a tumor without ulcer or differentiated type (approximately equal intestinal type) cT1a $(\leq 3 \mathrm{~cm})$ tumor with ulcer, and the expanded indication [16] is undifferentiated type (approximately equal diffuse type) cT1a $(\leq 2 \mathrm{~cm})$ tumor without ulcer. Furthermore, the lesion out of indication for endoscopic resection is subjected to surgical resection. In Japan, many institutions employ laparoscopic surgery, as it is minimally invasive, for surgical resection for cT1 lesion. For lesions endoscopically resected, the degree of cure is determined by the pathological diagnosis after endoscopic resection and the subsequent treatment policy (including laparoscopic gastrectomy) is determined. This flow of indications is based on endoscopic T-category, biopsy histology, and endoscopically resected tumor histology rather than the clinical stage. Thus, endoscopic determination of T-category may be of great clinical significance.

The introduction of MDCT and endoscopic ultrasonography (EUS) has increased the accuracy of the clinical diagnosis and has had an effect on therapy selection $[17,18]$; in particular, EUS is recommended in the National Comprehensive Cancer Network guidelines [2]. Although EUS is a moderately accurate imaging modality in terms of elucidating tumor depth in GC [19], conventional endoscopy also enables a distinction to be made between EGC and AGC. Moreover, EUS is not available in all institutions, and the sensitivity and specificity of EUS have been reported to range widely [20, 21]. Further, some previous studies have suggested that conventional endoscopy could achieve a similar degree of accuracy than that of EUS [22-24], and were conducted using conventional endoscopy in an effort to differentiate between EGC and AGC [25]. Therefore, the guidelines of the JGES have suggested that the T-category diagnosis is more generally performed by conventional endoscopy and proposed to use EUS in a supplementary fashion to diagnose whether the tumor is $\mathrm{T} 1 \mathrm{a}$ or $\mathrm{T} 1 \mathrm{~b}$ [26]. In our institution, we first classify GC into EGC or AGC with conventional endoscopy and then perform EUS or high-magnification endoscopy for further assessment, if necessary, according to the above guidelines. Furthermore, we used CT or PET/CT for preoperative diagnosis to evaluate serosal invasion or invasion of adjacent organ, $\mathrm{N}$ factor, and $\mathrm{M}$ factor. EUS for gastric cancer was performed in 27 cases (cEGC: 22 cases; cAGC: 5 cases) in our institution during the same period as this study. There was no case with a different T-category between the conventional endoscopy and EUS, and only 2 of 22 cases diagnosed as cEGC were Early-look $\mathrm{AGC}(\mathrm{pT} 2)$.

Regarding tumor site localization, the nature of the GC tumor has been reported to differ depending on its location [27]. Lee et al. suggested that a longitudinal location might affect the accuracy of the endoscopic examination [25]. Recently, the importance of evaluating not only the longitudinal location but also the cross-sectional location has been suggested [11]. However, few studies to date have focused on the cross-sectional location; Jung et al. examined the relationship between the cross-sectional location and clinicopathological features, but only for EGC [11]. Therefore, we integrated both longitudinal and cross-sectional localizations of GC. To our knowledge, the present study is the first report to examine in detail the relationship between longitudinal and crosssectional locations and the accuracy of clinical diagnosis of tumor depth in patients with GC. When longitudinal localization was stratified according to the UM and L regions in cAGC, we noted significantly more frequent occurrences of Advanced-look EGC cases in the latter $(p=0.021)$, while, in $c E G C$, we noted a tendency for more frequent occurrences of Early-look AGC cases in the former $(p=0.067)$. In addition, although no significant difference was found when comparing the four cross-sectional location groups, we did find a tendency for more frequent occurrences of Early-look AGC cases in PL regions among cEGC patients $(p=0.065)$. Therefore, in the present study, we focused on the L region in the context of cAGC and the UM-PL region in the context of cEGC, respectively. In the cEGC group, a UM-PL region was chosen as a predictor for an Early-look AGC case status in the multivariate analysis. The reason for underdiagnosis in the UM-PL region was not clear; however, we did not observe significant clinicopathological characteristics of the tumor despite the high frequency of Early-look AGC cases in this region. These results suggest that the biological characteristics of cancer may differ depending on the site affected in the stomach. Among the cAGC cases, we found that an L region was significantly associated with an Advanced-look EGC status. This region is known to be associated with both peptic ulcers and ulcerated GC. This association may explain the overdiagnosis by preoperative endoscopic assessment in cases with a coexisting peptic ulcer in the $\mathrm{L}$ region [28]. Over-staging also harbors a risk for the patient; surgical over-treatment can lead to higher postoperative dysfunction or complication rates. Therefore, a strategy is required to improve the diagnostic accuracy of endoscopy, such as a repeated preoperative endoscopic assessment after the administration of medical treatment for a peptic ulcer in an L-region location. 
Fig. 2 Prognostic factors according to the pre- and postoperative T-categories in patients with GC. Kaplan-Meier curves for the RFS (top) and OS (bottom) rates of GC patients according to the pre- and postoperative $\mathrm{T}$ categories

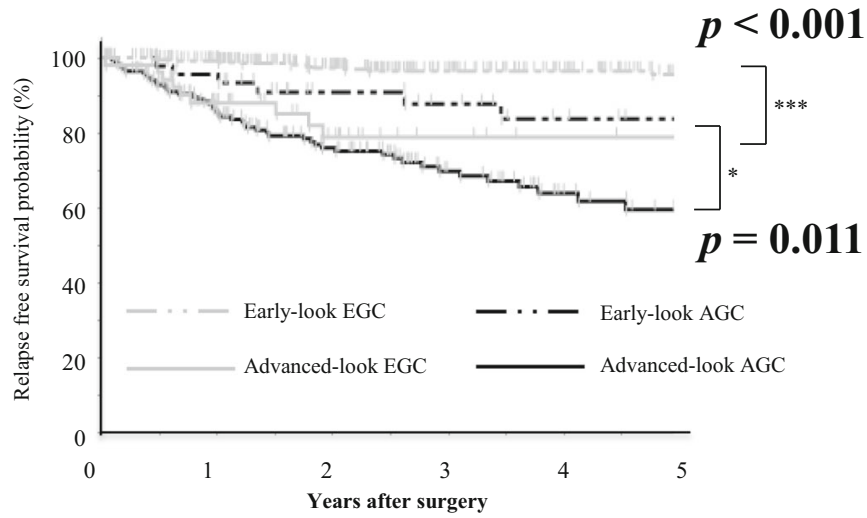

Patients at risk
Early-look EGC

Advanced-look EGC Early-look AGC Advanced-look AGC

$\begin{array}{ccc}180 & 141 & 102 \\ 14 & 10 & 9 \\ 26 & 20 & 16 \\ 55 & 32 & 24\end{array}$

02
9
16
24

.

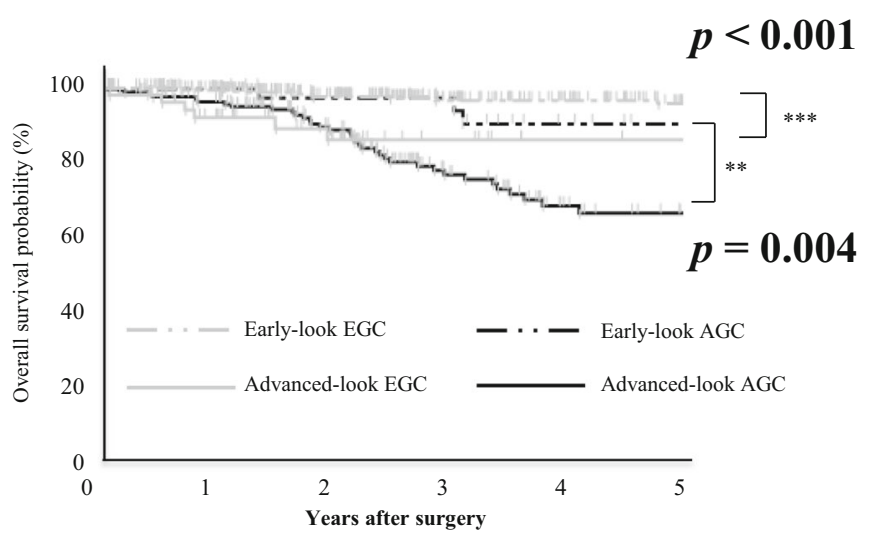

Patients at risk

Early-look EGC

Advanced-look EGC Early-look AGC Advanced-look AGC 
[31]. Supportively to this previous report, our study demonstrated that an Advanced-look EGC status was also an independent prognostic factor for RFS of pEGC. cAGC appears to be a critical biological factor in patients with pEGC (Advanced-look EGC), and patients with this diagnosis might be considered for adjuvant chemotherapy a high-risk group for $\mathrm{pEGC}$. Therefore, further research is necessary to ensure the adequacy of D1 plus dissection for Early-look-AGC cases or adjuvant chemotherapy for Advanced-look EGC cases.

The present study had some limitations that must be mentioned. First, it was limited by a small sample size, which prevented us from drawing more concrete conclusions regarding the accuracy of the tumor localization assessment and determination of the therapeutic strategy based on the preoperative assessment. Further studies involving a larger number of patients are warranted. However, the present study did demonstrate the clinical potential of clinical staging of tumor depth.

\section{Conclusion}

The accuracy of clinical assessments varies with tumor localization in GC. Clinical diagnosis of EGC or AGC is likely to have a strong impact on patient prognosis based on the choice of therapeutic modalities. Therefore, clinician needs to make a strategy in consideration of possible overstaging or understaging depending on tumor localization. Further research is needed to clarify which diagnosis should be emphasized to decide the treatment when clinical and pathological Tcategories are different.

Authors' contributions This study was designed by K.N., K.S., T.K., and E.O.; K.N., K.S., and T.K. performed statistical analyses; the clinical information and materials were collected and kept by K.N., K.S., T.K., T.K., H.K., A.S., H.F., K.O., and E.O.; K.N., K.S., and T.K. drafted the manuscript; T.K., H.K., A.S., H.F., K.O., and E.O. edited and revised the manuscript; K.N., K.S., T.K., T.K., H.K., A.S., H.F., K.O., and E.O. approved the final version of the manuscript; K.N., K.S., T.K., T.K., H.K., A.S., H.F., K.O., and E.O. agreed to be accountable for all aspects of the work.

\section{Compliance with ethical standards}

Conflict of interest The authors declare that they have no conflict of interest.

Ethical approval All procedures performed in studies involving human participants were in accordance with the ethical standards of the institutional research committee and with the 1964 Helsinki declaration and its later amendments or comparable ethical standards.

Informed consent Informed consent was obtained from all individual participants included in the study.

Open Access This article is licensed under a Creative Commons Attribution 4.0 International License, which permits use, sharing, adaptation, distribution and reproduction in any medium or format, as long as you give appropriate credit to the original author(s) and the source, provide a link to the Creative Commons licence, and indicate if changes were made. The images or other third party material in this article are included in the article's Creative Commons licence, unless indicated otherwise in a credit line to the material. If material is not included in the article's Creative Commons licence and your intended use is not permitted by statutory regulation or exceeds the permitted use, you will need to obtain permission directly from the copyright holder. To view a copy of this licence, visit http://creativecommons.org/licenses/by/4.0/.

\section{References}

1. Bray F, Ferlay J, Soerjomataram I, Siegel RL, Torre LA, Jemal A (2018) Global cancer statistics 2018: GLOBOCAN estimates of incidence and mortality worldwide for 36 cancers in 185 countries. CA Cancer J Clin 68:394-424

2. The National Comprehensive Cancer Network (NCCN) Clinical Practice Guidelines in Oncology (NCCN Guidelines $\left.{ }^{\circledR}\right)$. Available: https://www.nccn.org/professionals/physician_gls/ default.aspx [accessed March 24, 2019]

3. Japanese Gastric Cancer Association (2017) Japanese gastric cancer treatment guidelines 2014 (ver. 4). Gastric Cancer 20:1-19

4. Cardoso R, Coburn N, Seevaratnam R et al (2012) A systematic review and meta-analysis of the utility of EUS for preoperative staging for gastric cancer. Gastric Cancer 15:S19-S26

5. Hamilton R, Aatonen LA (2000) Tumors of digestive system. IARC, Lyon, pp 39-52

6. Gotoda T, Yanagisawa A, Sasako M, Ono H, Nakanishi Y, Shimoda T, Kato Y (2000) Incidence of lymph node metastasis from early gastric cancer: estimation with a large number of cases at two large centers. Gastric Cancer 3:219-225

7. Hirasawa T, Gotoda T, Miyata S, Kato Y, Shimoda T, Taniguchi H, Fujisaki J, Sano T, Yamaguchi T (2009) Incidence ofł lymph node metastasis and the feasibility of endoscopic resection for undifferentiated - type early gastric cancer. Gastric Cancer 12:148-152

8. Kim W, Kim HH, Han SU, Kim MC, Hyung WJ, Ryu SW, Cho GS, Kim CY, Yang HK, Park DJ, Song KY, Lee SI, Ryu SY, Lee JH, Lee HJ (2016) Decreased morbidity of laparoscopic distal gastrectomy compared with open distal gastrectomy for stage I gastric cancer: short-term outcomes from a multicenter randomized controlled trial (KLASS-01). Ann Surg 263:28-35

9. Katai H, Mizusawa J, Katayama H, Takagi M, Yoshikawa T, Fukagawa T, Terashima M, Misawa K, Teshima S, Koeda K, Nunobe S, Fukushima N, Yasuda T, Asao Y, Fujiwara Y, Sasako M (2017) Short-term surgical outcomes from a phase iii study of laparoscopy-assisted versus open distal gastrectomy with nodal dissection for clinical stage IA/IB gastric cancer: Japan Clinical Oncology Group Study JCOG0912. Gastric Cancer 20:699-708

10. Choi E, Roland JT, Barlow BJ, O'Neal R, Rich AE, Nam KT, Shi C, Goldenring JR (2014) Cell lineage distribution atlas of the human stomach reveals heterogeneous gland populations in the gastric antrum. Gut 63:1711-1720

11. Jung YJ, Seo HS, Kim JH, Park CH, Lee HH (2017) Crosssectional location of gastric cancer affects the long-term survival of patients as tumor invasion deepens. Ann Surg Oncol 24:3947-3953

12. Brierley JD, Gospodarowicz MK, Wittekind C (eds) (2017) Union for International Cancer Control. TNM classification of malignant tumors. 8th edn. Wiley, New York 
13. Japanese Gastric Cancer Association (2011) Japanese classification of gastric carcinoma: 3rd English edition. Gastric Cancer 14:101-112

14. Gotoda T, Iwasaki M, Kusano C, Seewald S, Oda I (2010) Endoscopic resection of early gastric cancer treated by guideline and expanded National Cancer Centre Criteria. Br J Surg 97:868-871

15. Hasuike N, Ono H, Boku N et al (2018) A non-randomized confirmatory trial of an expanded indication for endoscopic submucosal dissection for intestinal-type gastric cancer (cT1a): the Japan Clinical Oncology Group Study (JCOG0607). Gastric Cancer 21: 114-123

16. Takizawa K, Takashima A, Kimura A, Mizusawa J, Hasuike N, Ono H, Terashima M, Muto M, Boku N, Sasako M, Fukuda H, Gastrointestinal Endoscopy Study Group (GIESG) of Japan Clinical Oncology Group (JCOG), Stomach Cancer Study Group (SCSG) of Japan Clinical Oncology Group (JCOG) (2013) A phase II clinical trial of endoscopic submucosal dissection for early gastric cancer of undifferentiated type: Japan Clinical Oncology Group Study JCOG1009/1010. Jpn J Clin Oncol 43:87-91

17. Nagpal P, Prakash A, Pradhan G, Vidholia A, Nagpal N, Saboo SS, Kuehn DM, Khandelwal A (2017) MDCT imaging of the stomach: advances and applications. Br J Radiol 90:20160412. https://doi. org/10.1259/bjr.20160412

18. Nie RC, Yuan SQ, Chen XJ, Chen S, Xu LP, Chen YM, Zhu BY, Sun XW, Zhou ZW, Chen YB (2017) Endoscopic ultrasonography compared with multidetector computed tomography for the preoperative staging of gastric cancer: a meta-analysis. World J Surg Oncol 15:113

19. Furukawa K, Miyahara R, Itoh A, Ohmiya N, Hirooka Y, Mori K, Goto H (2011) Diagnosis of the invasion depth of gastric cancer using MDCT with virtual gastroscopy: comparison with staging with endoscopic ultrasound. AJR Am J Roentgenol 197:867-875

20. Lee HH, Lim CH, Park JM, Cho Y, Song K, Jeon H, Park C (2012) Low accuracy of endoscopic ultrasonography for detailed T staging in gastric cancer. World J Surg Oncol 10:190

21. Kwee RM, Kwee TC (2007) Imaging in local staging of gastric cancer: a systematic review. J Clin Oncol 25:2107-2116
22. Matsumoto Y, Yanai H, Tokiyama H, Nishiaki M, Higaki S, Okita K (2000) Endoscopic ultrasonography for diagnosis of submucosal invasion in early gastric cancer. J Gastroenterol 35:326-331

23. Choi J, Kim SG, Im JP, Kim J, Jung H, Song I (2010) Comparison of endoscopic ultrasonography and conventional endoscopy for prediction of depth of tumor invasion in early gastric cancer. Endoscopy 42:705-713

24. Choi J, Kim SG, Im JP, Kim JS, Jung HC, Song IS (2011) Endoscopic prediction of tumor invasion depth in early gastric cancer. Gastrointest Endosc 73:917-927

25. Lee JH, Lee KN, Kim HI et al (2016) Discordant findings between preoperative endoscopy and postoperative pathology as an independent prognostic factor in gastric cancer patients. Surg Endosc 7: 2743-2750

26. Yao K, Uedo N, Kamada T et al (2019) Japanese endoscopic diagnosis guideline for early gastric cancer. Gastroenterol Endosc 61: 1283-1319

27. Shim JH, Song KY, Jeon HM et al (2014) Is gastric cancer different in Korea and the United States? Impact of tumor location on prognosis. Ann Surg Oncol 21:2332-2339

28. Akashi K, Yanai H, Nishikawa J et al (2006) Ulcerous change decreases the accuracy of endoscopic ultrasonography diagnosis for the invasive depth of early gastric cancer. Int J Gastrointest Cancer 37:133-138

29. Sun Z, Wang ZN, Zhu GL, Huang BJ, Li K, Xu Y, Li DM, Xu HM (2010) Advanced gastric cancer with early cancer macroscopic appearance: is it worthy of D2 lymphadenectomy? Ann Surg Oncol 17:1278-1290

30. Ito Y, Kanada M, Ito S et al (2020) Prognosis after laparoscopic gastrectomy in patients with pathological stage II or III gastric cancer who were preoperatively diagnosed with clinical stage I: propensity score matching analysis of a multicenter dataset. Ann Surg Oncol 27:268-275

31. Kitamura K, Yamaguchi T, Nishida S, Yamamoto K, Okamoto K, Taniguchi H, Hagiwara A, Sawai K, Takahashi T (1997) Early gastric cancer mimicking advanced gastric cancer. Br J Cancer 75:1769-1773

Publisher's note Springer Nature remains neutral with regard to jurisdictional claims in published maps and institutional affiliations. 